\title{
Effect of Different Wine-Making Techniques on the Composition and Quality of Pinotage Wine. II. Juice/Skin Mixing Practices
}

\author{
J. Marais* \\ ARC Infruitec-Nietvoorbij, Private Bag X5026, 7599 Stellenbosch, South Africa
}

Submitted for publication: February 2003

Accepted for publication: July 2003

Key words: Pinotage, punching-down, pumping-over, rotor action, esters, phenolic compounds, wine quality

\begin{abstract}
The effect of different juice/skin mixing practices (punching-down of the cap, pumping-over of the juice and the rotor action, and the frequency at which these actions were performed) on Pinotage wine composition and quality, was investigated over three seasons (2000 to 2002). Wines were analysed for total polyphenols (flavonoids, tannins, anthocyanins) and esters, and sensorially evaluated for Pinotage cultivar character (berry/plum) intensity and overall wine quality. The punching-down and rotor treatments yielded the highest, and the pumping-over treatment the lowest total polyphenol concentrations. Although it appeared that the 3-hourly action yielded slightly higher polyphenol concentrations than the 1-hourly action, no statistical differences were observed between the two treatments. Irrespective of season, the rotor treatment yielded the highest acetate ester concentrations. The corresponding wines reflected the individual treatments to a great extent, and in general the wine qualities of the punching-down and rotor treatments were of the same order, but higher than those of the pumping-over treatment. Wine quality did not differ significantly between the 1- and 3-hourly treatments, irrespective of the mixing technique and season.
\end{abstract}

Vitis viniferaL. cv. Pinotage [Pinot noir x Cinsaut noir (Hermitage)] is a unique South African cultivar, producing wines with distinctive fruity characters, described as plum-, cherry-, red berry-, black berry- and banana-like. Knowledge about the composition of Pinotage grapes and wines is lacking. Therefore research focuses on the development of technology that will optimise grape and wine composition and quality.

The occurrence of flavonoids, tannins and anthocyanins, as well as fermentation-formed acetate esters in young Pinotage wines was discussed in a concurrent investigation on the effect of lowtemperature skin contact prior to fermentation on Pinotage wine composition and quality (Marais, 2003). Mixing of juice and skins during fermentation for the extraction of phenolic and aroma components is also of the utmost importance. Different mixing practices (punching-down of the cap, pumping-over of the juice and the rotor action) exist and the method of preference usually depends on availability of technology. To the best of my knowledge, comparison of different juice/skin mixing treatments has not been reported before.

The purpose of this study was to determine the effect of different juice/skin mixing practices on Pinotage wine composition and quality, MATERIALS AND METHODS

\section{Grapes}

Pinotage grapes from the same vineyard on the Nietvoorbij farm (Stellenbosch region), were used during three seasons (2000 to 2002). In all cases grapes were harvested at approximately $23^{\circ} \mathrm{B}$ to $24^{\circ} \mathrm{B}$.

\section{Grape treatments and wine-making}

Grapes were divided into three equal, representative lots (each 9 cases $=180 \mathrm{~kg}$ ) and stored overnight at $15^{\circ} \mathrm{C}$. After storage, each ${ }^{\circ}{ }^{3}$ was destemmed, crushed, $50 \mathrm{mg} / \mathrm{L}$ total $\mathrm{SO}_{2}$ added, inoculated with Saccharomyces cerevisiae strain WE 14 (Anchor Bio-Technologies) and fermented dry at $25^{\circ} \mathrm{C}$. During fermentation, three mixing treatments were conducted, i.e. punching-down of the cap with a wooden plunger, pumping-over of the juice (imitated by racking the juice into a bucket and pouring it over the skins) and the rotor action (imitated by rolling drums, filled with the crushed grapes, once to and fro by hand over a $5 \mathrm{~m}$ distance). Each treatment was conducted hourly and 3 hourly, respectively, between 07:00 and 19:00 until the fermentation was completed. The control was the punching-down hourly treatment. The whole experiment was done in triplicate. Wine-making was completed according to standard Nietvoorbij procedures for small-scale, red wine production. No malolactic fermentation and wood contact were conducted. Samples for analyses were collected daily until fermentation was completed.

\section{Polyphenols}

Total flavonoids, total tannins and total anthocyanins were extracted from the samples of the juice/skin mixtures and wines, and analysed spectrophotometrically according to the method of Di Stefano et al. (1989), as adapted by Nicolini \& Valenti (2001).

\section{Esters}

Esters were extracted from the wines by Freon 11 and the extracts analysed gas chromatographically (Marais, 1986). The esters analysed were iso-butyl acetate, iso-amyl acetate, hexyl acetate, ethyl butyrate, ethyl hexanoate, ethyl octanoate and ethyl decanoate. Wine quality

Wines were sensorially evaluated six months after production for berry/plum intensity and overall wine quality by a panel of six experienced judges. A line method was used, i.e. evaluating the

\footnotetext{
*E-mail address: johannm@infruit.agric.za

Acknowledgements: Technical contributions by Ewarda Swart, Francois October, Adele Louw and Christopher Paulse, as well asfinancial support by the South African Wine Industry (Winetech), the Pinotage Association and the Agricultural Research Council are appreciated.
} 
berry/plum intensity and overall wine quality by making a mark on an unstructured, straight $10 \mathrm{~cm}$ line. The left-hand and right-hand ends of the line were indicated respectively by the terms, "undetectable" and "prominent" for intensity, and by "unacceptable" and "excellent" for quality. Wines were also ranked according to the above-mentioned wine quality characteristics. Treatments (punching-down, pumping-over, rotor action), as well as treatment frequencies (every 1 and 3 hours) were compared separately.

\section{Statistical analyses}

Statistical differences between treatments were determined by applying standard analysis of variance methods to the data. Least significant differences (LSD) were calculated to facilitate comparison between treatment means (Snedecor \& Cochran, 1980).

\section{RESULTS AND DISCUSSION}

\section{Polyphenols}

In general, differences in extraction rates of each phenolic group, namely total flavonoids, tannins and anthocyanins, between
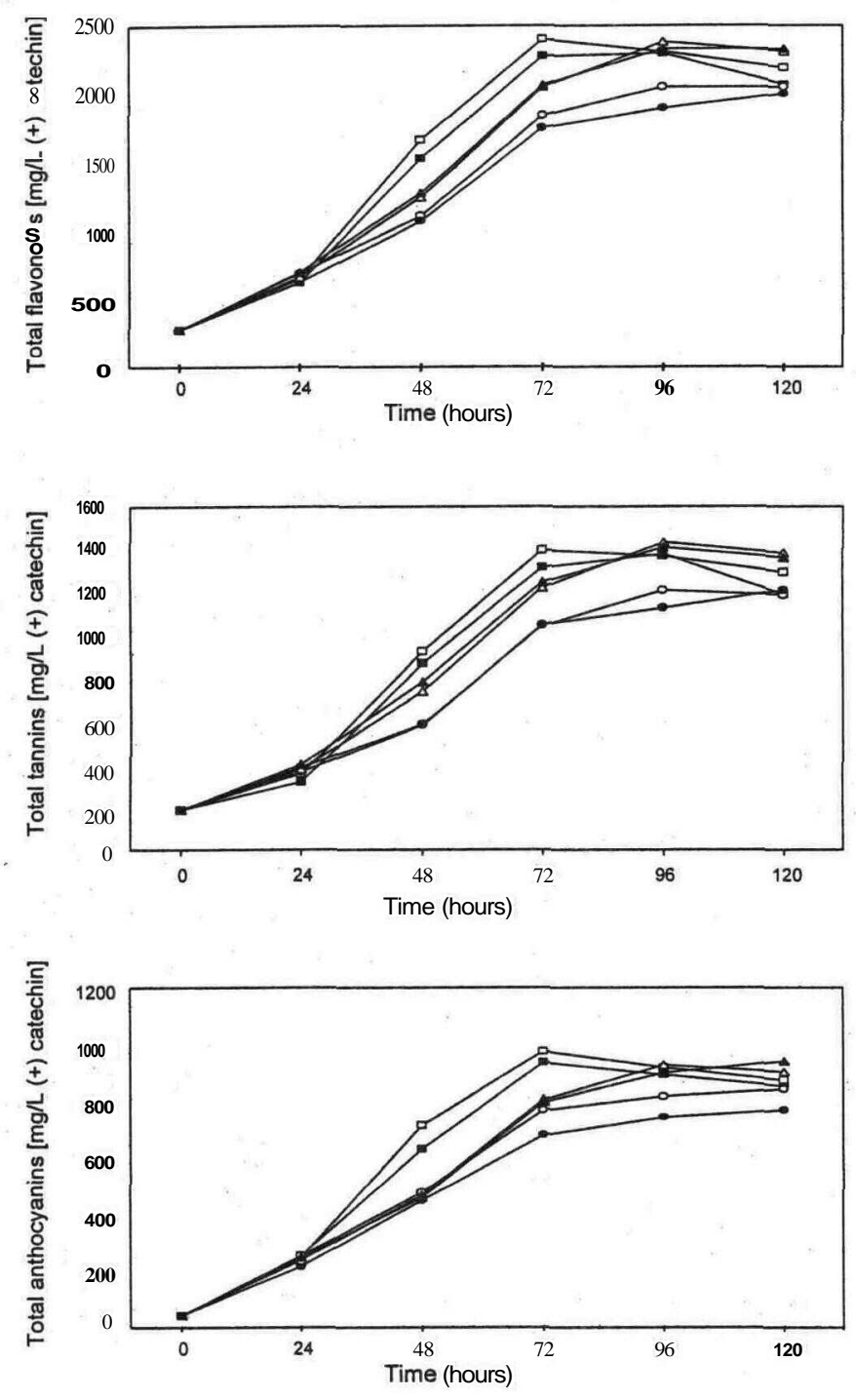

FIGURE 1

Effect of punching-down, pumping-over and rotor treatments on flavonoid, tannin and anthocyanin extraction in Pinotage juice/wine (2002 season).

$\mathrm{o}=$ Punching-down every 1 hour; $\bullet=$ Punching-down every 3 hours; $\mathrm{o}=$ Pumping-over every 1 hour; $\boldsymbol{0}=$ Pumping-over every 3 hours; $\mathrm{A}=$ Rotor action every 1 hour; ; $\mathbf{\Delta}=$ Rotor action every 3 hours. punching-down, pumping-over and rotor actions, were minimal (Fig. 1). This observation also applied to differences between 1and 3-hourly actions. Generally, a plateau was reached at approximately 96 hours. The 2002 trends were representative of trends obtained over the whole experimental period.

With regard to the bottled wines, total polyphenol concentrations were highest and approximately of the same order for the punchingtdown and rotor, and lowest for the pumping-over, treatments (Fig. 2). This phenomenon may be ascribed to the fact that pumping-over is a softer action and, additionally, a higher degree of oxygen contact probably led to polymerisation and precipitation of certain phenolic components. Varying trends between 1- and 3-hourly treatments were observed, but differences were minimal.

\section{Esters}

Young Pinotage wines are characterised by relatively high concentrations of fermentation bouquet volatiles, especially iso-amyl acetate (Van Wyk et al., 1979). When in moderate concentrations,
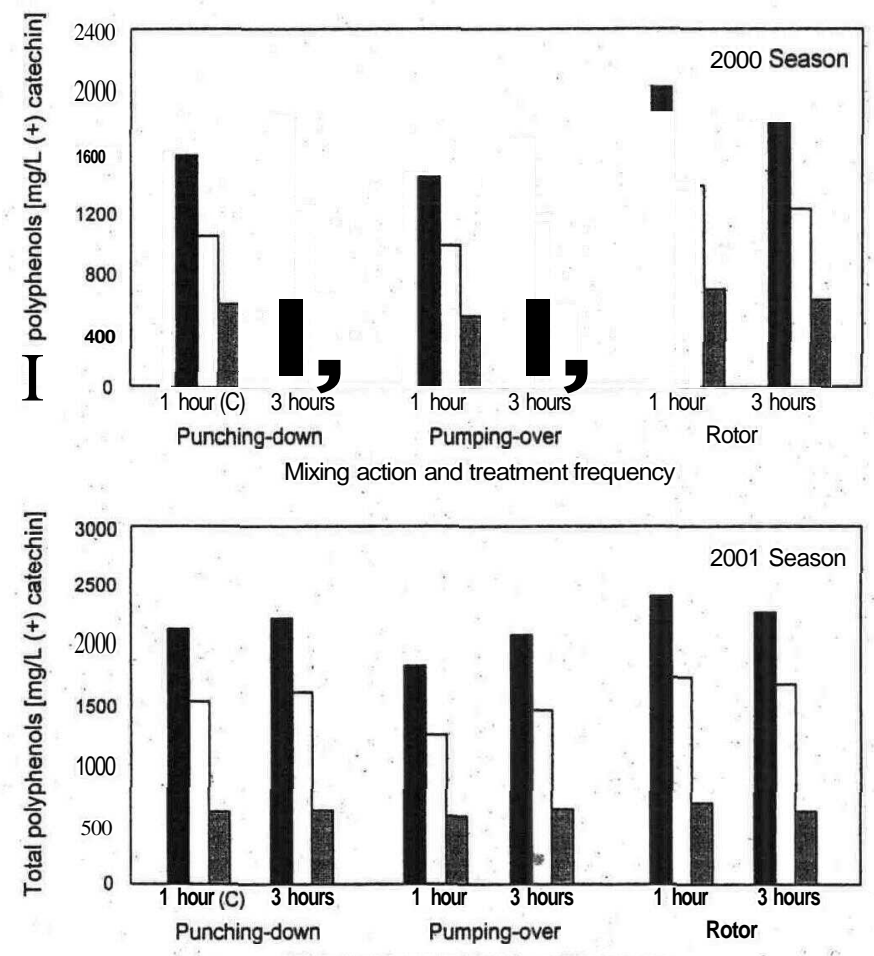

Mixing action and treatment frequency

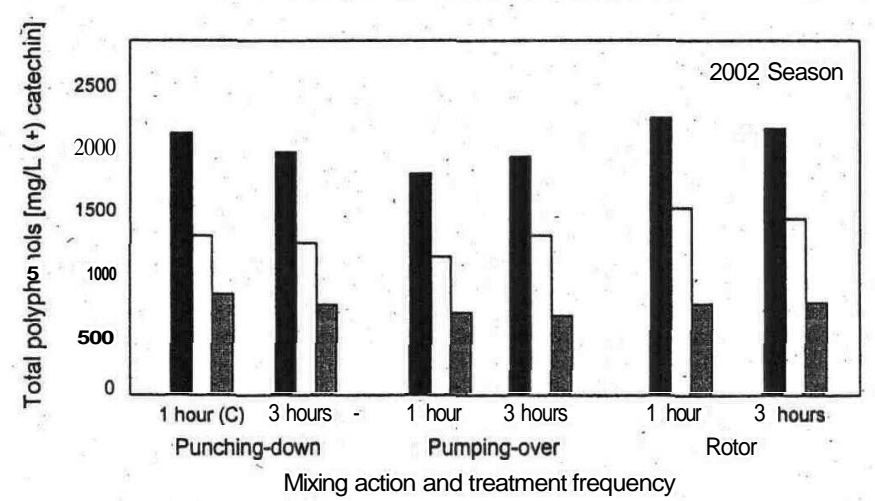

FIGURE 2

Effect of punching-down, pumping-over and rotor actions on total polyphenol concentrations in Pinotage wines.

= Total flavonoids; $\mathrm{C}=$ Total tannins; $\mathrm{I}=$ Total anthocyanins. 

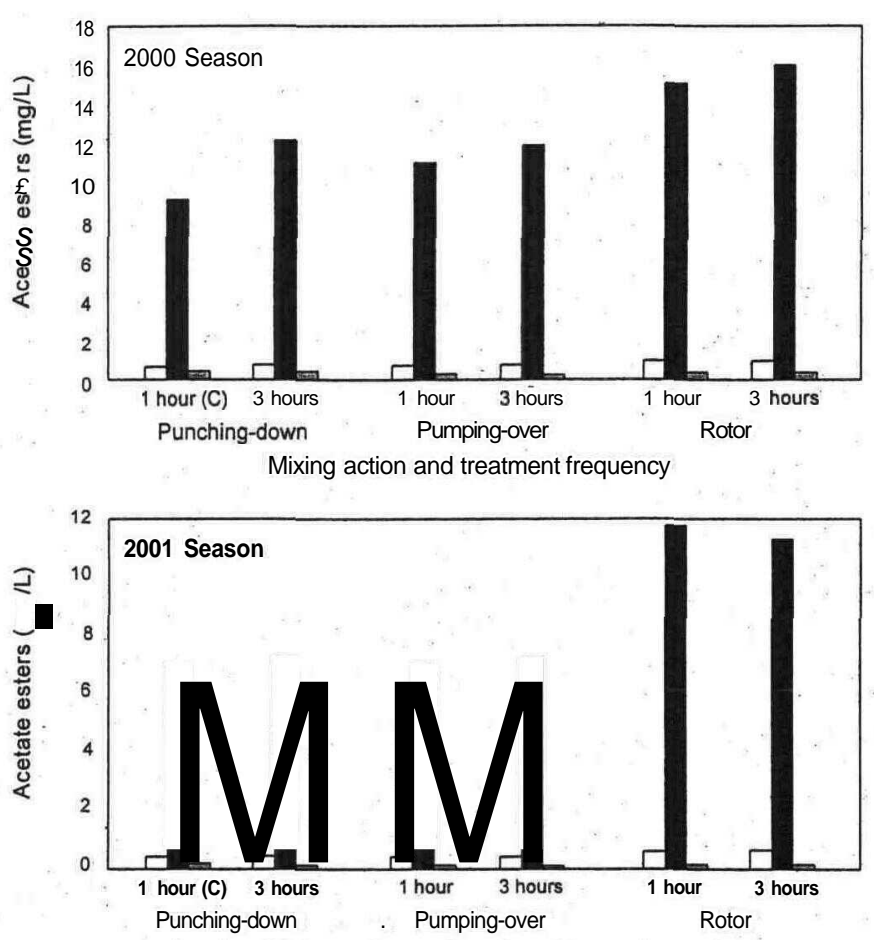

Mixing action and treatment frequency

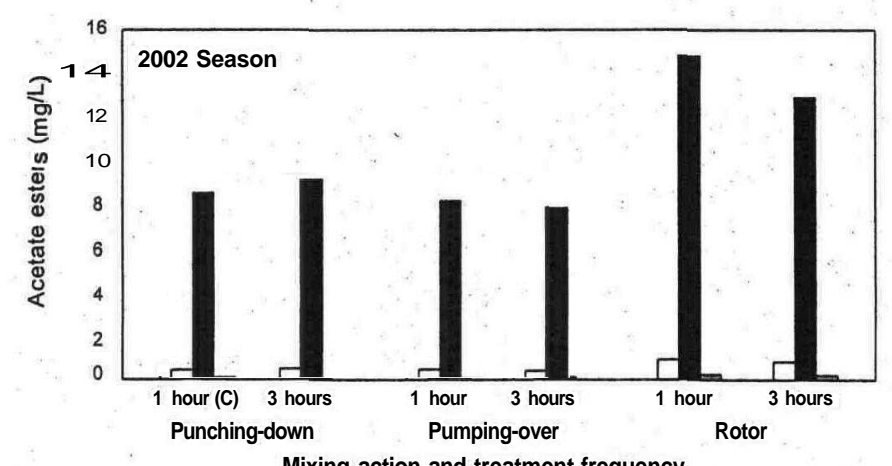

FIGURE 3

Effect of punching-down, pumping-over and rotor actions on acetate ester concentrations in Pinotage wines..

$\mathrm{D}=$ iso-Butyl acetate; $\bullet=$ iso-Amyl acetate; $\mathbf{E}=$ Hexyl acetate.

this component is responsible for a pleasant banana-like aroma, but in too high concentrations it can exhibit a negative "nail-polish/duco"-like character. The banana-like aroma was not prominent in the wines and was therefore not evaluated. With respect to acetate esters, the rotor action clearly produced the highest values (Fig. 3). This phenomenon may be ascribed to the fact that the rotor system (drum) was mostly a closed system and was only opened during daily samplings. Varying tendencies were observed between the 3- and 1-hourly treatments. Similar tendencies were obtained for ethyl esters (data not shown).

Differences in the measured component levels between seasons are naturally ascribed to differences in grape composition at harvest caused by differences in climatic conditions and grape maturity?

\section{Wine quality}

The above-mentioned trends in phenolic and ester concentrations and naturally other non-measured component concentrations were
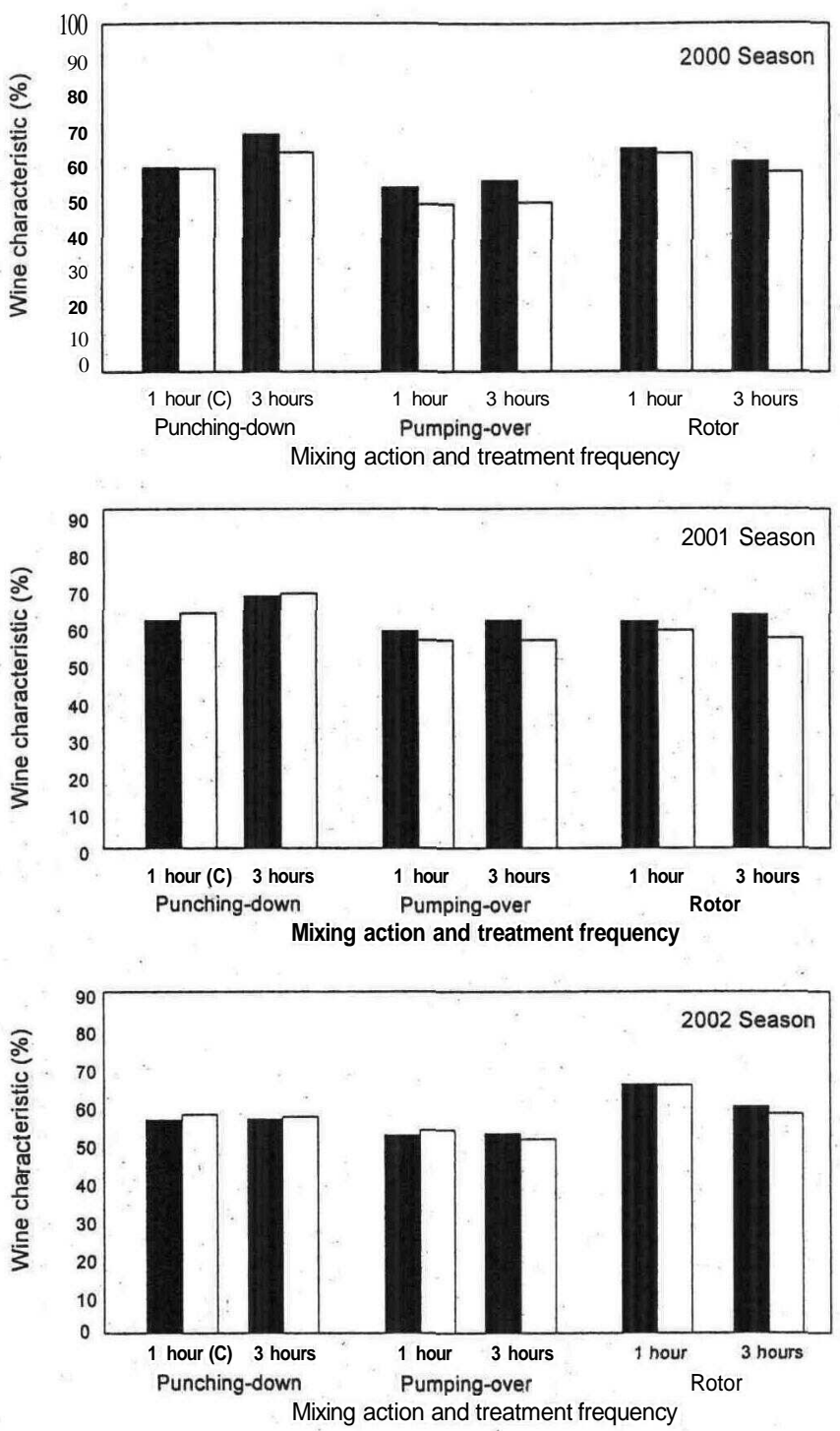

FIGURE 4

Effect of punching-down, pumping-over and rotor actions on Pinotage wine quality. - = Berry/plum intensity; $\mathrm{D}=$ Overall wine quality.

reflected in the qualities of the corresponding wines. The highest qualities were obtained for the punching-down and rotor treatments, and, generally, only slight differences between 1- and 3hourly treatments were observed (Fig. 4). These observations apply to the typical berry/plum character intensity, as well as to overall wine quality. Sensory ranking of the wines confirmed individual evaluation results. Irrespective of season and treatment frequency, the rotor treatment yielded the highest quality wines, and the pumping-over treatment the lowest quality wines (data not shown).

When the effect of the three mixing treatments, irrespective of treatment frequency, and vice versa the effect of the treatment frequency, irrespective of mixing treatment, were analysed, the above-mentioned chemical and sensory evaluation results were statistically confirmed (Tables 1 and 2).

It can be deduced that, under the conditions of this investigation, the punching-down and rotor treatments yielded higher quality wines than the pumping-over treatment. 
TABLE 1

Effect of mixing treatments (averages of two treatment frequencies - 1 and 3 hours) on Pinotage wine composition and quality (2000 2002 seasons).

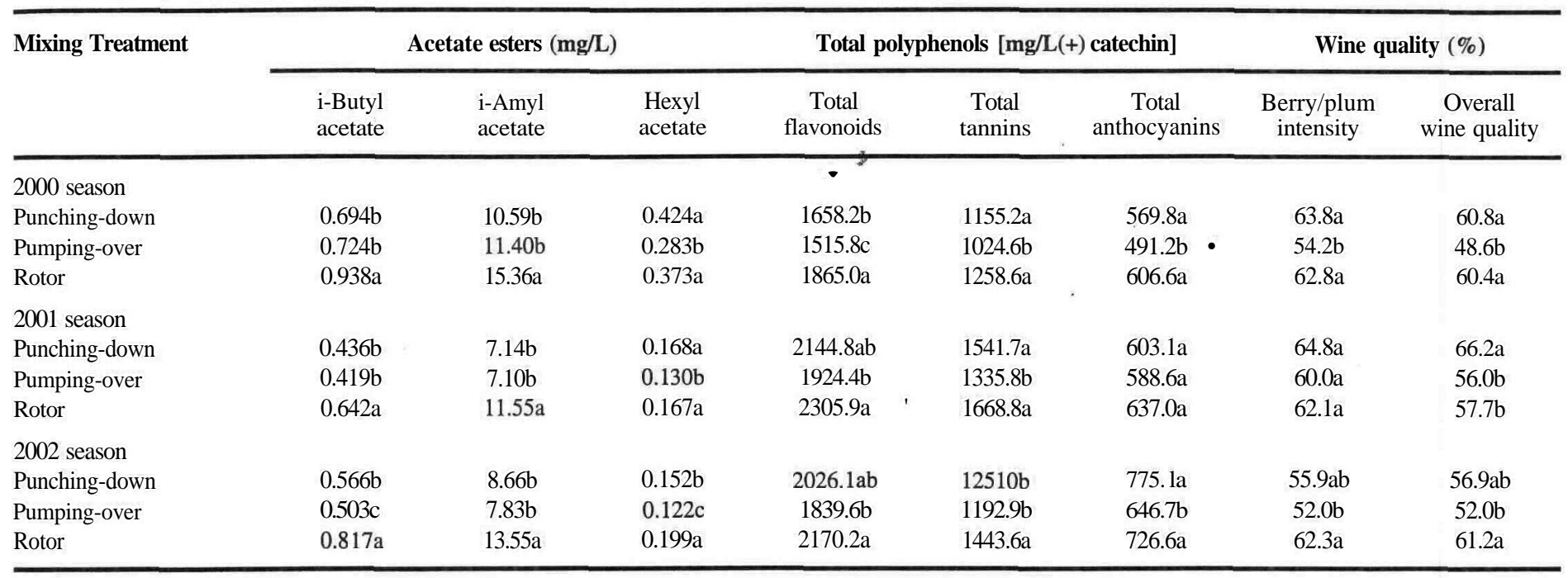

Treatments designated by the same letter do not differ significantly $(\mathrm{p}<0.05)$ (each season, aroma component, phenolic group and wine quality characteristic viewed separately).

\section{TABLE 2}

Effect of treatment frequencies (averages of three mixing treatments - punching-down, pumping-over and rotor action) on Pinotage wine composition and quality (2000 - 2002 seasons).

\begin{tabular}{|c|c|c|c|c|c|c|c|c|}
\hline \multirow{2}{*}{$\begin{array}{l}\text { Treatment } \\
\text { Frequency (hrs) }\end{array}$} & \multicolumn{3}{|c|}{ Acetate esters $(\mathbf{m g} / \mathbf{L})$} & \multicolumn{3}{|c|}{ Total polyphenols [mg/L(+) catechin] } & \multicolumn{2}{|c|}{ Wine quality (\%) } \\
\hline & $\begin{array}{l}\text { i-Butyl } \\
\text { acetate }\end{array}$ & $\begin{array}{l}\text { i-Amyl } \\
\text { acetate }\end{array}$ & $\begin{array}{c}\text { Hexyl } \\
\text { acetate }\end{array}$ & $\begin{array}{c}\text { Total } \\
\text { flavonoids }\end{array}$ & $\begin{array}{c}\text { Total } \\
\text { tannins }\end{array}$ & $\begin{array}{c}\text { Total } \\
\text { anthocyanins }\end{array}$ & $\begin{array}{l}\text { Berry/plum } \\
\text { intensity }\end{array}$ & $\begin{array}{c}\text { Overall } \\
\text { wine quality }\end{array}$ \\
\hline \multicolumn{9}{|l|}{2000 season } \\
\hline 1 & $0.744 \mathrm{a}$ & $11.64 \mathrm{a}$ & $0.376 \mathrm{a}$ & $1640.0 \mathrm{~b}$ & $1134.0 \mathrm{a}$ & $550.6 \mathrm{a}$ & $59.0 \mathrm{a}$ & $56.6 \mathrm{a}$ \\
\hline 3 & $0.827 \mathrm{a}$ & $13.26 \mathrm{a}$ & $0.344 \mathrm{a}$ & $1719.2 \mathrm{a}$ & $1158.2 \mathrm{a}$ & $561.0 \mathrm{a}$ & $61.5 \mathrm{a}$ & $56.6 \mathrm{a}$ \\
\hline \multicolumn{9}{|l|}{2001 season } \\
\hline 1 & $0.492 \mathrm{a}$ & 8.61a & $0.169 \mathrm{a}$ & 2091.1a & $1480.7 \mathrm{a}$ & $610.4 a$ & $60.4 \mathrm{a}$ & $59.4 \mathrm{a}$ \\
\hline 3 & $0.505 \mathrm{a}$ & $8.59 \mathrm{a}$ & $0.141 b$ & $2158.9 \mathrm{a}$ & $1550.1 \mathrm{a}$ & $608.7 \mathrm{a}$ & $64.2 \mathrm{a}$ & $60.5 \mathrm{a}$ \\
\hline \multicolumn{9}{|l|}{2002 season } \\
\hline 1 & $0.633 \mathrm{a}$ & $10.27 \mathrm{a}$ & $0.178 \mathrm{a}$ & $2034.6 \mathrm{a}$ & $1298.3 \mathrm{a}$ & $736.3 \mathrm{a}$ & $57.6 \mathrm{a}$ & $58.3 \mathrm{a}$ \\
\hline 3 & $0.624 \mathrm{a}$ & $9.75 \mathrm{a}$ & $0.137 \mathrm{~b}$ & $1989.4 a$ & $1293.4 \mathrm{a}$ & $696.0 \mathrm{a}$ & $55.9 \mathrm{a}$ & $55.0 \mathrm{a}$ \\
\hline
\end{tabular}

Treatments designated by the same letter do not differ significantly ( $\mathrm{p}<0.05$ ) (each season, aroma component,phenolic group and wine characteristic viewed separately).

\section{CONCLUSIONS}

Mixing techniques during fermentation have a marked effect on Pinotage wine composition and quality. Under the conditions of this investigation, mixing ofjuice and skins during fermentation by punching-down and rotor actions yielded the most typical and highest quality Pinotage wines. These techniques are therefore recommended. However, pumping-over may be a suitable technique as well, since it yields wines with a softer structure. The choice of mixing technique will also depend on the maturity at which grapes are harvested. Therefore it is important that wineries should test these mixing treatments on a commercial scale under their specific conditions, before a specific technique is used. Differences in wine quality between 1- and 3-hourly treatments were not significant under the conditions of this study. This finding is important with respect to the financial implications where extra manpower and electricity are involved in the higher treatment frequencies.

\section{LITERATURE CITED}

Di Stefano, R., Cravero, M.C. \& Gentilini, N., 1989. Metodi per lo studio dei polifenoli dei vini. L'Enotecnico 25, 83-89.

Marais, J., 1986. A reproducible capillary gas chromatographic technique for the determination of specific terpenes in grape juice and wine. S. Afr.J. Enol. Vitic. 7, 21-25.

Marais, J., 2003. Effect of different wine-making techniques on the composition and quality of Pinotage wine. I. Low-temperature skin contact prior to fermentation. S. Afr. J. Enol. Vitic. 24, 70-75.

Nicolini, G. \& Valenti, L., 2001. Indagine sul corredo polifenolico di vini Sagrantino con metodiche applicábili ai controllidi processo. Riv. Vitic. Enol. 54, $49-65$.

Snedecor, G.W. \& Cochran, W.G., 1980. Statistical methods. 7th Edition. The IOWA State University Press. pp. 253-254.

Van Wyk, C.J., Augustyn, O.P.H., De Wet, P. \& Joubert, W.A., 1979. Isoamylacetate - A key fermentation volatile of wines of Vitis vinifera $\mathrm{cv}$ Pinotage. Am. J. Enol. Vitic. 30, 167-173. 